\title{
Identifying the pre-malignant stomach: from guidelines to practice
}

\author{
Jonathan R. White ${ }^{1,2}$, Matthew Banks ${ }^{3,4}$ \\ ${ }^{1}$ NIHR Nottingham Biomedical Research Centre, Nottingham University Hospitals NHS Trust and the University of Nottingham, Nottingham, \\ UK; ${ }^{2}$ Nottingham Digestive Diseases Centre, The University of Nottingham, Nottingham, UK; ${ }^{3}$ University College London Hospital, University \\ College London Hospitals NHS Foundation Trust, London, UK; ${ }^{4}$ Research Department of Targeted Intervention, University College London, \\ London, UK \\ Contributions: (I) Conception and design: None; (II) Administrative support: None; (III) Provision of study materials or patients: None; (IV) \\ Collection and assembly of data: None; (V) Data analysis and interpretation: None; (VI) Manuscript writing: Both authors; (VII) Final approval of \\ manuscript: Both authors. \\ Correspondence to: Jonathan R. White. NIHR Nottingham Biomedical Research Centre, Nottingham University Hospitals NHS Trust and the \\ University of Nottingham, Nottingham, UK. Email: jonathan.white@nottingham.ac.uk.
}

\begin{abstract}
Gastric adenocarcinoma develops after stepwise progression from normal mucosa through to adenocarcinoma most commonly after being triggered by Helicobacter pylori (H. pylori) infection. As disease is often diagnosed late, the prognosis for gastric adenocarcinoma is poor. Identifying pre-malignant mucosal lesions such as atrophic gastritis, intestinal metaplasia and dysplasia is one strategy adopted by clinicians to reduce cancer related mortality. Surveillance of high-risk individuals and endoscopic resection of dysplastic lesions is recommended by international and UK guidelines. The early detection and endoscopic management reduce the need for invasive surgery. The advancement of image enhanced endoscopy technology, endoscopic training, risk stratification and histological assessment has proven pivotal to the management of pre-malignant lesions. In this review we outline the development of a high-risk stomach, endoscopic assessment and review practical guidelines on identifying pre-malignant gastric mucosa.
\end{abstract}

Keywords: Premalignant; atrophic gastritis; intestinal metaplasia; dysplasia; gastric adenocarcinoma; Helicobacter pylori $(H$. pylori); endoscopy

Received: 16 September 2019; Accepted: 14 November 2019; Published: 25 January 2022.

doi: $10.21037 /$ tgh.2020.03.03

View this article at: http://dx.doi.org/10.21037/tgh.2020.03.03

\section{Introduction}

Gastric adenocarcinoma is a significant global health concern especially in developing countries. Worldwide it is the fifth most common malignancy and ranked the third commonest cause of cancer related death $(1,2)$. Diagnosis is usually at a late stage, therefore, both the worldwide and UK 5 -year survival rate is under $30 \%$ and $20 \%$ respectively $(3,4)$. Despite the poor prognosis associated with late diagnosis clinicians fail to identify on average $15 \%$ of gastric cancers and some studies report miss rates up to $25 \%(5-7)$.

There are two subtypes defined by location. The first type is of the cardia, which originates from the gastroesophageal junction, and shares similar risk factors to oesophageal adenocarcinoma (1). The second type, non- cardia, arises from the distal stomach. Helicobacter pylori $(H$. pylori) infection is implicated in over $60 \%$ of non-cardia gastric adenocarcinomas (8).

Histologically, there are two types of adenocarcinoma. Firstly, the intestinal type which is believed to develop from an inflammation driven gradual progression from $H$. pylori gastritis through to atrophic gastritis, intestinal metaplasia, dysplasia and finally to adenocarcinoma $(9,10)$. The second type is a diffuse type and the mechanism is likely to be triggered by $H$. pylori but is not associated with intestinal metaplasia and usually affects young individuals $(11,12)$. There are a number of truly hereditary cases of gastric cancer accounting for $1-3 \%$ of all gastric adenocarcinoma cases and include hereditary diffuse gastric cancer (HDGC), familial intestinal gastric cancer (FIGC) and other single- 
gene syndromes associated with a possible increased risk of gastric adenocarcinoma.

Atrophic gastritis is also associated with type 1 gastric neuroendocrine tumours via a different cellular pathway. The annual incidence of type 1 gastric neuroendocrine tumours is approximately $0.4 \%$ (13).

Cancer incidence and mortality rates have steadily declined but the exact reasons are not fully known. Dietary improvement, decline in $H$. pylori rates, screening of highrisk countries and reduced tobacco smoking rates may have contributed (14). Despite this decline, gastric cancer still has a significant impact on the global economy (15). One strategy for reducing the mortality associated with gastric cancer is the surveillance of individuals at risk with the goal to detect cancer at an earlier stage and offer less invasive endoscopic treatment (16). The gold standard for detecting premalignant changes such as atrophic gastritis, intestinal metaplasia and dysplasia in the stomach is histology. Recent advances in endoscopy techniques have aided detection and risk stratification of atrophic gastritis and gastric intestinal metaplasia.

Recently published UK guidelines and updated international guidelines are now available to aid management. There are multiple achievable performance measures outlined to achieve a high-quality endoscopic examination $(17,18)$. However, despite the international guidelines being available since 2012 practice still varies widely across the UK. In this review we provide an overview of identification of the premalignant stomach and current practical guidelines.

\section{Development of the pre-malignant stomach}

\section{Helicobacter pylori (H. pylori)}

This spiral bacterium was first isolated from the inflamed human stomach in the 1980's (19). H. pylori colonizes the gastric mucosa in childhood and generally persists lifelong without treatment (20). Half the world's population are colonized with the bacterium but the majority of individuals remain asymptomatic (21). Chronic infection leads to locally inflamed gastric mucosa termed gastritis. H. pylori infection leads to oxidative damage from the production of reactive oxygen and nitrogen species (22). The level and pattern of inflammation determines disease risk and outcome (23). $H$. pylori is the trigger in the stepwise cascade from chronic gastritis to atrophic gastritis, intestinal metaplasia and ultimately to dysplasia (24). The initial stage is the inflammatory response to injury with the recruitment of lymphoid tissue and neutrophils to the gastric mucosa (10). The following phase is cell apoptosis and proliferation, where the rate of cell loss is greater than proliferation causing mucosal thinning leading to atrophic gastritis. Further architectural and genetic changes eventually lead to the progression to more advanced stages and ultimately cancer (25). A patient's risk of progression to atrophic gastritis and cancer is determined by bacterial, host and environmental factors (26). Although eradication therapy reduces both atrophic gastritis incidence, and also gastric cancer incidence, there may be a point of no return where eradication is unhelpful along the cancer cascade. Current high-quality data suggest that while eradication of $H$. pylori reduces subsequent gastric adenocarcinoma risk in patients who have non-atrophic or gastric atrophy, these benefits are not consistently maintained in patients who have developed gastric intestinal metaplasia, dysplasia or cancer (27-31).

\section{Atrophic gastritis}

The normal gastric mucosa consists of gastrin and mucus secreting cells located in the antrum. In addition to pepsinogen and acid secreting cells located in the corpus. Atrophic gastritis occurs when there is loss of these specialised cells and replacement with fibrous tissue and metaplastic glands (32). Both atrophic gastritis and intestinal metaplasia are epithelial precancerous conditions as they both increase the risk of dysplasia and cancer development $(16,33)$. Histologically, atrophic gastritis features include the presence of lymphocytes, plasma cells (which impact on the lamina propria) and loss of specialised gastric glands. However, pathologist inter-observer agreement on the presence and severity of atrophic gastritis if often low especially when assessing gland loss $(34,35)$. There have been multiple proposed ways to grade atrophic gastritis. The Operative Link on Gastritis Assessment (OLGA) and Operative Link on Gastritis Assessment based on Intestinal Metaplasia (OLGIM) are two recommended methods of assessments. OLGIM grades III and IV can accurately identify at risk individuals that warrant surveillance (16). A recent meta-analysis has provided evidence that these two assessment tools are valid and reliable for predicting the risk of progression (36). Serological markers of atrophic gastritis and upper GI endoscopy have been used to determine prevalence (37). This varies between $0 \%$ and $8 \%$ in the west and is influenced by age $(33,38)$. In areas where there is a high incidence of $H$. pylori this is much higher between $33 \%$ 
Table 1 Gastric cancer risk for pre-malignant stomach

\begin{tabular}{llll}
\hline Pre-malignant mucosa & Annual incidence & 5 -year cancer incidence & References \\
\hline Severe gastric atrophy & & $10 \%$ & Zullo et al. [2012] (42) \\
Mild gastric atrophy & & $0.7 \%$ & de Vries et al. [2008] (46) \\
All grades of gastric atrophy & $<0.5 \%$ & $<2 \%$ & de Vries et al. [2008] (46) \\
& & & Song et al. [2015] (49) \\
Antral \& corpus intestinal metaplasia & & $10 \%$ & Shichijo et al. [2016] (31) \\
Antral intestinal metaplasia & $5 \%$ & Shichijo et al. [2016] (31) \\
All grades intestinal metaplasia & $<0.4 \%$ & & Spence et al. [2017] (41) \\
& & 4 months to 2-year interval & de Vries et al. [2008] (46) \\
High grade dysplasia & $6 \%$ & $60-85 \%$ & de Vries et al. [2008] (46) \\
Low grade dysplasia & $0.6 \%$ & $0-23 \%$ & Sung et al. [2016] (50)
\end{tabular}

Table adapted from Banks et al. [2019] (33).

and $84 \%(33,39)$. The annual incidence of progression from atrophic gastritis to adenocarcinoma is $0.1-0.25 \%$ for all stages of the condition, and risk increases with the extent of atrophy. There is, however, wide variability in the incidence due small patient cohorts in single centre studies (16,40-42).

\section{Gastric Intestinal metaplasia}

Metaplasia is the transformation of normal mucosal epithelium to a different epithelial type. This is commonly found in the stomach and termed intestinal metaplasia. It is due to chronic injury to the mucosa. In complete intestinal metaplasia, mucosa exhibits goblet and absorptive cells, reduced levels of gastric and intestinal mucins. The mucosa at the incomplete stage is populated by goblet and nonabsorptive columnar cells with expression of both gastric and intestinal mucins. Incomplete types are generally more extensive (25).

European prevalence of intestinal metaplasia is under 19\% and is influenced by rates of $H$. pylori infection, age, smoking status and family history of gastric cancer $(33,43-45)$. The annual incidence of gastric cancer in patients with intestinal metaplasia is $0.25 \%$ for all stages of the condition (46). The risk is dependent on the extent and type of intestinal metaplasia (47). The two less extensive intestinal metaplasia distribution can be described as focal (consisting of scattered areas of intestinal metaplasia predominately in the lesser curvature and incisura) or antrum predominant (confined to antrum and incisura). The more extensive types include 'magenstrasse' (intestinal metaplasia which involves the lesser curvature of the stomach) and 'diffuse' involving the entire stomach with the exception of the fundus (48) (see Table 1).

\section{Gastric dysplasia}

This is the final stage in the carcinogenesis sequence and is characterised by neoplastic epithelium without tissue invasion termed dysplasia. Dysplasia is classified as low or high grade depending on the architectural and cellular atypia. When carcinoma invades the lamina propria with structural abnormalities this is termed intramucosal carcinoma. High grade dysplasia are at increased risk of harbouring intramucosal carcinoma and with an increased risk of lymphatic invasion (51). The prevalence for all grades of gastric dysplasia is between $0.5 \%$ and $20 \%$ depending on the background prevalence of $H$. pylori and gastric cancer $(49,50,52,53)$. The annual incidence for developing gastric cancer from a diagnosis of high-grade dysplasia within 5 years of diagnosis is $6 \%$ (46).

\section{Gastric polyps with malignant potential}

Adenoma and hyperplastic polyps have a malignant potential. Adenomatous gastric polyps are sessile or pedunculated polyps that can progress to gastric adenocarcinoma if untreated. Histologically, there are three types; tubular, villous and tubulovillous. The prevalence in the west varies between $0.5 \%$ and $10 \%$ depending on the area studied (33). 
These are commonly found in the antrum and are associated with gastric atrophy (54). Malignant potential increases with size larger than $20 \mathrm{~mm}$ and with a patient's age (55).

Hyperplastic polyps are usually smooth sessile or pedunculated with fibrin exudate polyps, and maybe coated with erosions. When examined histologically they may contain parietal and chief cells with lengthened foveolar cells. These are usually found in the antrum, are associated with $H$. pylori gastritis and may regress following eradication (55). Malignant transformation occurs in $2 \%$ patients in post resection stomachs or if polyps are greater than $10 \mathrm{~mm}$ (56).

Other polyps with a malignant potential include hamartomatous polyps associated with Peutz-Jeghers' syndrome and gastric neuroendocrine tumours (carcinoids).

\section{Endoscopic features of the pre-malignant stomach}

\section{Endoscopic features of $\mathrm{H}$. pylori}

Chronically infected $H$. pylori gastric mucosal tissue at time of endoscopy shows macroscopic nodularity, gastric fold hypertrophy and magnified alteration in vascular density such as loss of collecting venules and subepithelial capillary network (57-60). Results for magnified endoscopy for the diagnosis of $H$. pylori gastritis are variable but some prospective studies have demonstrated sensitivity and specificity between $60 \%$ and $100 \%(59,60)$. Currently histology or non-invasive urea breath testing remain the gold standard for $\mathrm{H}$. pylori detection as endoscopy features are often limited and not reproducible (61).

\section{Endoscopic features of atrophic gastritis}

Multifocal atrophy usually first develops in the incisura, then progresses along the antrum and corpus leading to widespread atrophy (62). The four principal endoscopic features of gastric atrophy include pallor, loss of gastric folds, prominence of the vessels, and the atrophic border. Increased visibility of the vascular network showed a sensitivity of $48 \%$ and specificity of $87 \%$, while the loss of gastric folds has a sensitivity $67 \%$ and specificity of $85 \%$ (63-66).

These features are attributable to the loss of gastric mucosa and submucosa vascular visibility pattern in addition to mucosal swelling. These features showed AUC/ROC values of 0.70 and correlate well with the serological marker of atrophic gastritis in the form of pepsinogen I/II ratio (67).
Pepsinogen I and II are released from gastric mucosa secretory cells. A low pepsinogen I or pepsinogen I/II ratio under 3 correlates well with atrophy affecting the corpus. Multiple prospective studies have demonstrated sensitivity and specificity of serological markers in the range of 70-90\% (68-70). The Kimura-Takemoto classification tool is useful in the prediction of cancer development $(71,72)$. The risk is 2.7-9.3 times higher when comparing severe to none to moderate atrophy using this classification. This classification is, however, is complicated so is rarely used by western endoscopists (25).

Multiple advanced endoscopy techniques can be used to aid the accurate diagnosis of atrophic gastritis. Current techniques include high definition endoscopy with magnification, chromoendoscopy, autofluorescence imaging (AFI) and narrow band imaging (NBI).

Magnification endoscopy can produce magnified images greater than 100 times which allows surface mucosa and vascular structures to be clearly visualised $(59,73)$. The arrangement of surface glands, epithelium, vascular pattern and mucosal oedema are reflected in pit patterns. These gastric pits are the first to be altered in gastric lesions. In atrophic gastritis the pits change colour to white, enlarge and become encircled by erythema (58). Combining NBI with magnification can accurately identify atrophic mucosa $(68,74)$.

Chromoendoscopy involves the application of certain dyes such as methylene blue, indigo carmine or acetic acid which improve visualisation of gastric pre-malignant changes $(75,76)$.

AFI produces images based on the emission of excited light from structures such as collagen or porphyrins. Normal gastric mucosa appears purple. Loss of fundic glands in atrophic gastritis leads to an increase in intensity of AFI, thus the mucosa appears green and so the borders of the atrophy are more easily identified. Accuracy for detecting atrophic gastritis and intestinal metaplasia has been shown to be 0.88 and 0.81 respectively (77).

NBI produces a sharp contrast between mucosa and vascular structures leading to improved image detail (78). Combining NBI and AFI improves pre-malignant lesion detection (79). Shi et al. combined AFI and NBI and achieved a sensitivity and specificity between $83 \%$ and $99 \%$ for detecting intestinal metaplasia, dysplasia and early gastric cancer (80). Limitations of these techniques include the specialist training requirement; they are often limited to tertiary centres and can increase procedure times which may impact on a patient's tolerance. 

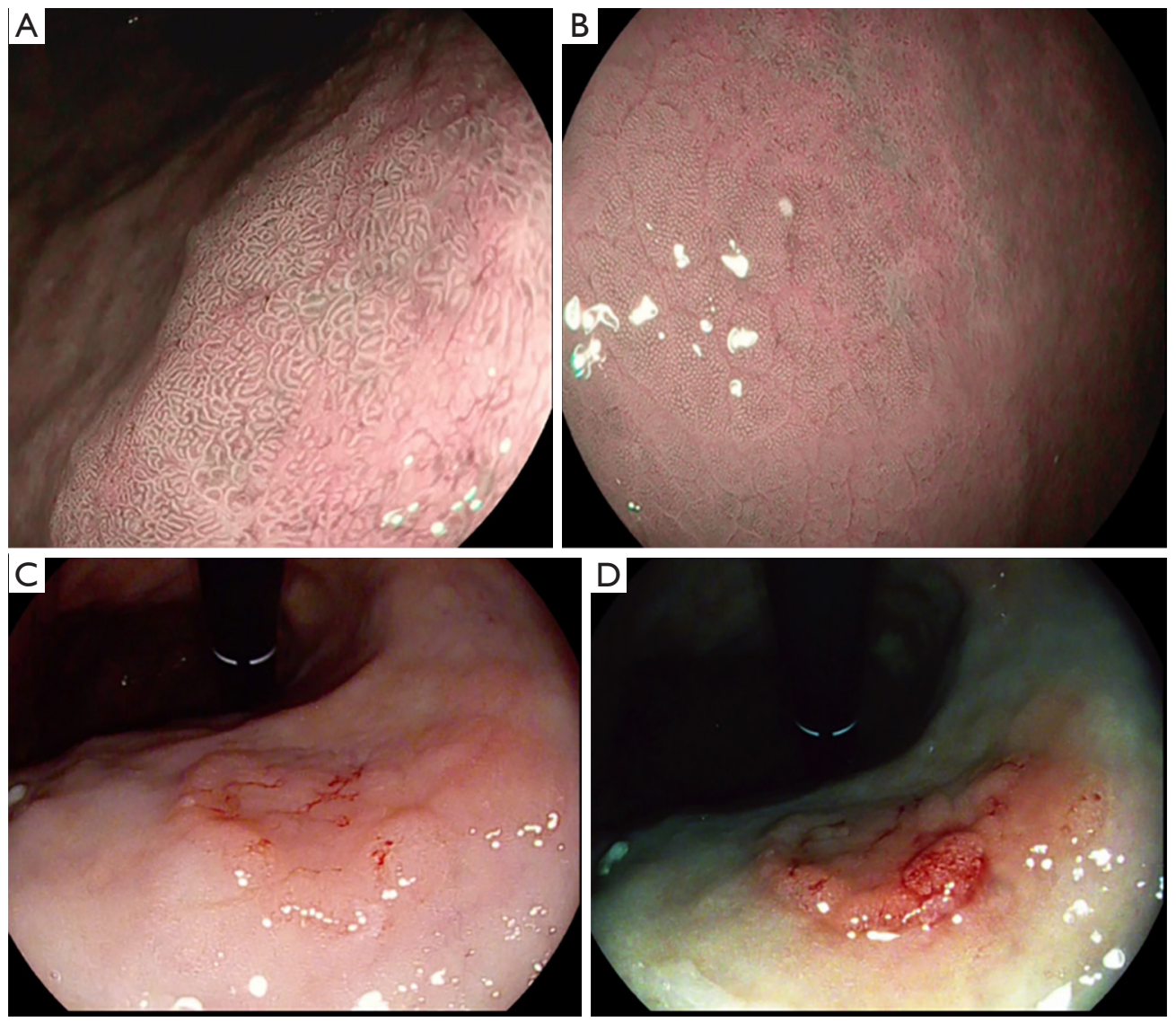

Figure 1 Gastric intestinal metaplasia and early gastric cancer. Gastric intestinal (A) and the atrophic border (B) seen using narrow band imaging endoscopy. Early gastric lesions seen in white light endoscopy (C) and image enhanced endoscopy (D).

\section{Endoscopic features of intestinal metaplasia}

The use of standard white light endoscopy (WLE) often shows poor correlation with histology in detecting premalignant changes $(66,81)$. Since the introduction of high definition gastroscopes detection has improved. Endoscopic macroscopic features include elevated greyish white patches surrounded by pale and normal colour gastric mucosa or blotchy patchy erythema (82). Lipid droplets termed white opaque substance (WOS) are an endoscopic marker of intestinal metaplasia and epithelial tumours (83). Patchy reflections of blue-white located on epithelial margins is termed the light blue crest. NBI magnified images of blue light crest has an accuracy of 0.91 for detecting intestinal metaplasia (84). When light blue crest and WOS were combined the sensitivity and specificity was $87 \%$ and $93.8 \%$ respectively (85). Pimentel-Nunes et al.'s new grading system termed endoscopic grading of gastric intestinal metaplasia (EGGIM) with a maximum score of 5 examines the whole mucosa, therefore, generating a better endoscopic assessment. The sensitivity and specificity of an EGGIM score of 5 was $94 \%$ and $95 \%$ respectively (61). An earlier classification which described tubulo-villous mucosa for intestinal metaplasia had an accuracy of $84 \%$ (60).

NBI with magnification is superior to standard WLE in detecting intestinal metaplasia (16). Sensitivity for detecting intestinal metaplasia was significantly greater when compared with WLE (87\% vs. $53 \%$; $\mathrm{P}<0.001)$ (61). Similar results have also been shown in a number of studies (86). However, Ang et al., a large multi-centre prospective randomised study demonstrated NBI increases detection but sensitivity was low at 59\% (87). Overall, studies have shown NBI to be most beneficial when combined with high definition WLE for diagnosis and examining extent of disease (49) (see Figure 1). 


\section{Endoscopic features of gastric dysplasia}

An optimal environment is required to detect pre-malignant gastric mucosa changes. The use of mucolytics such as acetylcysteine (Parvolex, Celltech, UK) and dimethicone (Infacol, Forrest Laboratories, UK) mixed with water improves visualisation. This is in addition to the variety of advanced endoscopy imaging techniques. Often dysplasia is detected after subtle endoscopic appearances such as depressed or elevated lesions, loss of vascular pattern or subtle colour changes (88). Histologically, dysplasia can be divided into adenomatous (which is usually located in the corpus), foveolar (located in the antrum) or a hybrid type. The foveolar type often presents as small depressed or flat areas (53).

Pimentel-Nunes et al. developed a simple endoscopic classification using low magnification NBI which predicted dysplasia with an accuracy of $95 \%$ (60). Kaise et al. investigated depressed lesions using NBI and concluded that abnormality in vascular and mucosal pattern were specific for cancer but the reproducibility was only moderate $(\mathrm{k}=0.48)(89)$. Multiple studies have concluded NBI improves detection when compared to WLE $(90,91)$. Meticulous examination of the mucosa pattern for irregular features is vitally important for detection of pre-malignant changes in clinical practice.

Although sometimes time consuming, Zhao et al.'s metaanalysis comparing chromoendoscopy to WLE reported a pooled sensitivity and specificity of $90 \%$ and $82 \%$ respectively for pre-malignant pathology (92). One downside to these studies are that inter-observer variability is sometimes not examined. Also, procedures are performed in tertiary centres in the hands of experts, often with pathology enriched study populations and therefore, are not generalisable.

\section{Pre-malignant stomach practical guidelines}

Dinis-Ribeiro et al. published the first international guidelines on the management of precancerous conditions and lesions in the stomach (MAPS) in 2012 and this was recently updated $(16,93)$. Due to the huge variability in practice in the UK, The British Society of Gastroenterology in 2019 produced UK guidelines (33). With both the international and UK guidelines, gastroenterologists now have easy access to the evidence and best practice for management of precancerous lesions. This should aid clinical management of pre-malignant conditions and if adopted universally may improve patient outcomes from gastric adenocarcinoma. Below is a summary of the main recommended practice guidance of identifying the pre-malignant stomach adopted from both the UK and international guidelines.

\section{Endoscopy assessment}

The Kimura-Takemoto classification is useful for determining cancer risk. Limitations include lack of routine use in western populations and moderate interobserver rating (94). This endoscopic method stratifies cancer risk by estimating atrophy extent and has not been included in either UK or international guidelines. However, UK guidelines recommend simple grading as distal and proximal gastric. Distal affects the antrum and incisura, and is deemed low risk. Whereas proximal gastric affects the corpus and may or may not include the antrum or incisura and is deemed high risk. To deliver high quality upper GI endoscopy UK quality guidelines have highlighted certain performance standards that should be met. Endoscopy should be performed with high definition images and the ability to obtain biopsy samples. All aspects of the gastric mucosa should be inspected and lesions comprehensively described. The use of mucosal cleansing techniques in combination with aspiration and insufflation is recommended to aid mucosal visualisation. Inspection times should be recorded. Procedures greater than 7 minutes have a 3-fold greater chance of detecting dysplastic or malignant lesions than shorter procedure times (95).

Lesion location and morphology using the Paris classification should be described prior to targeted histological sampling (17). The Paris classification observer agreement is moderate to good. Training using this classification in combination with NBI improves accuracy of lesion detection and observer agreement (91). Both UK and international guidelines for the pre-malignant stomach recommend the use of high definition with image enhanced technology and where possible magnification.

\section{Histological sampling}

Biopsies are taken from the antrum, incisura, lesser and greater curvatures of the stomach in the updated Sydney protocol $(96,97)$. High definition WLE is not sufficient for detection or risk stratification of pre-malignant gastric mucosa, therefore advanced endoscopy imaging techniques for targeted biopsy in addition to the Sydney protocol mapping biopsies should be used (98). 
Multiple studies have investigated random biopsies compared to NBI targeted biopsies. Xirouchakis et al. demonstrated random samples had a greater yield than NBI targeted. Accuracy for atrophic gastritis detection for WLE random verses NBI targeted was $93 \%$ vs. $80 \%(\mathrm{P}=0.03)(99)$. Non-targeted biopsies detect some mild or moderate premalignant changes that are not detected by NBI. In the hands of experts, NBI detects most severe pre-malignant cases without the need for sampling (16). Both UK and international guidelines recommend image enhanced targeted of suspicious areas and random sampling when assessing the pre-malignant stomach.

International guidelines recommend OLGA and OLGIM for staging, although this staging classification was derived from random biopsies and was considered too complex for generalised use in the UK, particularly given the inter-observer agreement was poor for OLGA and requires substantial training.

The annual incidence for developing gastric cancer with the autoimmune condition pernicious anaemia is less than $0.3 \%$ (100). The majority of the evidence for cancer risk is derived from case control studies. When atrophic gastritis is present for a number of years, the final process in its natural history is the development of pernicious anaemia (101). UK guidelines recommend corpus biopsies in patients suspected to have pernicious anaemia who present with low vitamin B12 levels and positive serology. International guidance recommends surveillance of autoimmune atrophic gastritis but specific recommendations on pernicious anaemia have not been made.

Biopsy sampling for $H$. pylori infection at the index endoscopy is highly recommended and especially important in young patients or those with mild atrophic gastritis.

\section{Serology biomarkers}

Serology markers of atrophic gastritis in combination with $H$. pylori serology are relatively inexpensive, non-invasive methods to determine the risk of developing cancer. One downside to $H$. pylori serology is the inability to differentiate between previous and current infection in a positive test. $H$. pylori bacterium cannot colonize mucosa with intestinal metaplasia or advanced atrophic gastritis. Lee et al. conducted a large prospective study in which patients were grouped according $H$. pylori and atrophy status by biopsies and serology. Patients with positive atrophic gastritis serology and negative $H$. pylori infection had the greater risk of developing gastric malignancy due to its clearance in the severely atrophic mucosa $(25,102)$. International guidance recommends use of pepsinogen serology to identify patients with severe atrophic gastritis. UK guidance does not recommend there use due to the low incidence of gastric cancer in UK. The use of serology is also not part of established practice in the UK.

\section{Surveillance}

Surveillance is carried out to detect the development of dysplasia or invasive carcinoma at an early stage with the aim of reducing morbidity and disease-specific mortality. Those with extensive atrophic gastritis or intestinal metaplasia affecting both antrum and corpus are offered 3 yearly surveillance. Areia et al.'s cost utility analysis demonstrated this strategy to be cost effective (103). The exact benefit of endoscopy surveillance in low gastric cancer incidence areas such as UK is unknown. Endoscopy is likely to remain the surveillance tool of choice unless more cost effective and non-invasive tools are developed.

Mild or moderate atrophic gastritis or intestinal metaplasia limited to the antrum does not require surveillance. If there are additional risk factors such as a first-degree relative strong family history or persistent $H$. pylori infection then 3-year surveillance could be adopted (see Figure 2).

Patients with no endoscopically visible lesion where lowor high-grade dysplasia is detected should undergo 12 and 6 monthly surveillance respectively. If a visible lesion is detected, this should be appropriately staged and resected either with an endoscopic mucosal resection (EMR) or endoscopic submucosal dissection (ESD) depending on the size. Although the evidence is weak, patients with autoimmune gastritis can be offered surveillance of between 3 to 5 years in the international guidance. UK guidance recommends patients with adenomatous or hyperplastic polyps have histological examination of the background mucosa for $H$. pylori infection or atrophic gastritis. Adenomas should be endoscopically resected and annual follow should be offered. Hyperplastic polyps greater than $10 \mathrm{~mm}$, or unchanged after $H$. pylori eradication or leading to symptoms should also be resected.

\section{Screening}

The rate of progression of Barrett's oesophagus to adenocarcinoma is slightly lower than gastric cancer but surveillance is well established and some countries offer screening (104). Endoscopic screening should be considered for patients with multiple risk factors for gastric 


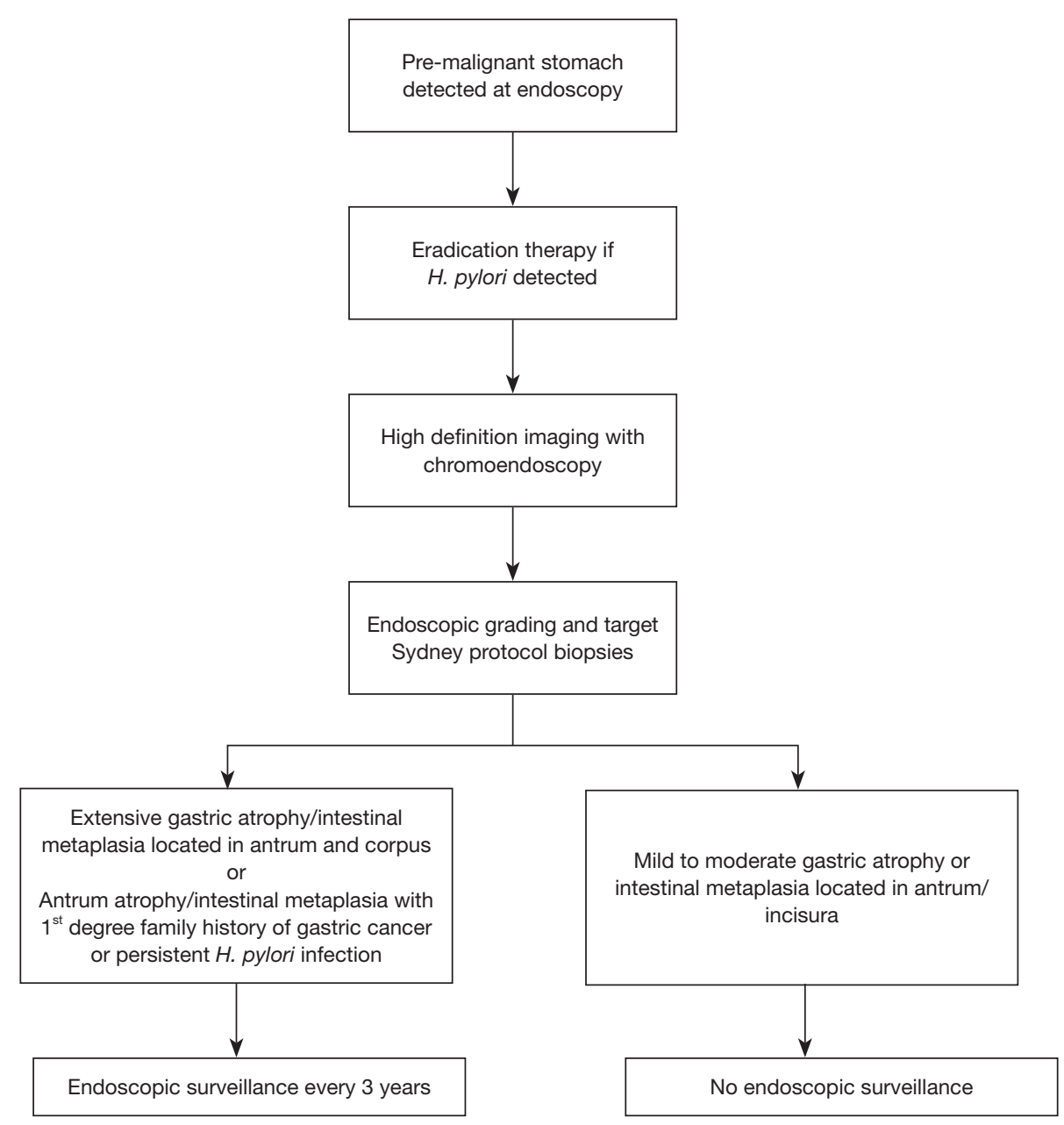

Figure 2 Gastric atrophy and intestinal metaplasia surveillance guidelines. Figure adapted from Banks et al. [2019] (33).

adenocarcinoma development. Population screening is not recommended in UK guidance, but international guidance recommends this in intermediate to high risk regions. Cost effective data from Asia suggest mass screening in high risk regions to be cost effective (105). H. pylori infection, family history, intestinal metaplasia and atrophic gastritis are strong risk factors for the development of gastric cancer. In moderate- to low-risk regions screening does not seem to be cost effective (106).

\section{Conclusions}

Gastric cancer develops from a well-recognised sequence from chronic gastritis to carcinoma. Atrophic gastritis, intestinal metaplasia and dysplasia carry a progressive increase in risk for cancer. Targeting these pre-malignant conditions is one strategy to improve the prognosis of gastric cancer which currently carries a poor prognosis. A variety of endoscopy modalities and advanced training of endoscopists can lead to earlier detection of pre-malignant lesions at a treatable stage. Most clinicians would offer surveillance at 3 yearly intervals but this approach is costly and alternative less invasive techniques are required for the future. Further research is needed in this area to determine optimal surveillance interval, application of universal endoscopy classification and the exact benefit of $H$. pylori 
eradication on cancer development.

\section{Acknowledgments}

Funding: JRW research is supported by the National Institute for Health Research (NIHR), through Nottingham Biomedical Research Centre, Nottingham University Hospitals NHS Trust and the University of Nottingham.

\section{Footnote}

Provenance and Peer Review: This article was commissioned by the Guest Editors (Krish Ragunath, Philip W. Y. Chiu) for the series "Advanced Endoscopic Imaging of the GI Tract" published in Translational Gastroenterology and Hepatology. The article has undergone external peer review.

Conflicts of Interest: Both authors have completed the ICMJE uniform disclosure form (available at https://tgh.amegroups. com/article/view/10.21037/tgh.2020.03.03/coif). The series "Advanced Endoscopic Imaging of the GI Tract" was commissioned by the editorial office without any funding or sponsorship. The authors have no other conflicts of interest to declare.

Ethical Statement: The authors are accountable for all aspects of the work in ensuring that questions related to the accuracy or integrity of any part of the work are appropriately investigated and resolved.

Open Access Statement: This is an Open Access article distributed in accordance with the Creative Commons Attribution-NonCommercial-NoDerivs 4.0 International License (CC BY-NC-ND 4.0), which permits the noncommercial replication and distribution of the article with the strict proviso that no changes or edits are made and the original work is properly cited (including links to both the formal publication through the relevant DOI and the license). See: https://creativecommons.org/licenses/by-nc-nd/4.0/.

\section{References}

1. Colquhoun A, Arnold M, Ferlay J, et al. Global patterns of cardia and non-cardia gastric cancer incidence in 2012. Gut 2015;64:1881-8.

2. Herrero R, Park JY, Forman D. The fight against gastric cancer - the IARC Working Group report. Best Pract Res Clin Gastroenterol 2014;28:1107-14.
3. Maconi G, Manes G, Porro GB. Role of symptoms in diagnosis and outcome of gastric cancer. World $\mathrm{J}$ Gastroenterol 2008;14:1149-55.

4. UK CR. Stomach cancer statistics Cancer Research UK 2016. Available online: http://www.cancerresearchuk.org/ health-professional/cancer-statistics/ statistics-by-cancertype/stomach-cancer. Accessed 24th July 2019.

5. Pimenta-Melo AR, Monteiro-Soares M, Libanio D, et al. Missing rate for gastric cancer during upper gastrointestinal endoscopy: a systematic review and metaanalysis. Eur J Gastroenterol Hepatol 2016;28:1041-9.

6. Hosokawa O, Hattori M, Douden K, et al. Difference in accuracy between gastroscopy and colonoscopy for detection of cancer. Hepatogastroenterology 2007;54:442-4.

7. Menon S, Trudgill N. How commonly is upper gastrointestinal cancer missed at endoscopy? A metaanalysis. Endosc Int Open 2014;2:E46-50.

8. Parkin DM. The global health burden of infectionassociated cancers in the year 2002. Int J Cancer 2006;118:3030-44.

9. Correa P. Helicobacter pylori and gastric carcinogenesis. Am J Surg Pathol 1995;19 Suppl 1:S37-43.

10. Correa P, Haenszel W, Cuello C, et al. A model for gastric cancer epidemiology. Lancet 1975;2:58-60.

11. Peek RM Jr, Blaser MJ. Helicobacter pylori and gastrointestinal tract adenocarcinomas. Nat Rev Cancer 2002;2:28-37.

12. White JR, Winter JA, Robinson K. Differential inflammatory response to Helicobacter pylori infection: etiology and clinical outcomes. J Inflamm Res 2015;8:137-47.

13. Vannella L, Sbrozzi-Vanni A, Lahner E, et al. Development of type I gastric carcinoid in patients with chronic atrophic gastritis. Aliment Pharmacol Ther 2011;33:1361-9.

14. Fock KM. Review article: the epidemiology and prevention of gastric cancer. Aliment Pharmacol Ther 2014;40:250-60.

15. Guy GP Jr, Ekwueme DU, Yabroff KR, et al. Economic burden of cancer survivorship among adults in the United States. J Clin Oncol 2013;31:3749-57.

16. Pimentel-Nunes $\mathrm{P}$, Libanio D, Marcos-Pinto R, et al. Management of epithelial precancerous conditions and lesions in the stomach (MAPS II): European Society of Gastrointestinal Endoscopy (ESGE), European Helicobacter and Microbiota Study Group (EHMSG), European Society of Pathology (ESP), and Sociedade 
Portuguesa de Endoscopia Digestiva (SPED) guideline update 2019. Endoscopy 2019;51:365-88.

17. Beg S, Ragunath K, Wyman A, et al. Quality standards in upper gastrointestinal endoscopy: a position statement of the British Society of Gastroenterology (BSG) and Association of Upper Gastrointestinal Surgeons of Great Britain and Ireland (AUGIS). Gut 2017;66:1886-99.

18. Bisschops R, Areia M, Coron E, et al. Performance measures for upper gastrointestinal endoscopy: a European Society of Gastrointestinal Endoscopy (ESGE) Quality Improvement Initiative. Endoscopy 2016;48:843-64.

19. Marshall BJ, Warren JR. Unidentified curved bacilli in the stomach of patients with gastritis and peptic ulceration. Lancet 1984;1:1311-5.

20. Blaser MJ, Atherton JC. Helicobacter pylori persistence: biology and disease. J Clin Invest 2004;113:321-33.

21. Peleteiro B, Bastos A, Ferro A, et al. Prevalence of Helicobacter pylori infection worldwide: a systematic review of studies with national coverage. Dig Dis Sci 2014;59:1698-709.

22. Hanada K, Graham DY. Helicobacter pylori and the molecular pathogenesis of intestinal-type gastric carcinoma. Expert Rev Anticancer Ther 2014;14:947-54.

23. Atherton JC. The pathogenesis of Helicobacter pyloriinduced gastro-duodenal diseases. Annu Rev Pathol 2006;1:63-96.

24. Correa P. Human gastric carcinogenesis: a multistep and multifactorial process--First American Cancer Society Award Lecture on Cancer Epidemiology and Prevention. Cancer Res 1992;52:6735-40.

25. Lage J, Uedo N, Dinis-Ribeiro M, et al. Surveillance of patients with gastric precancerous conditions. Best Pract Res Clin Gastroenterol 2016;30:913-22.

26. Waddingham W, Graham D, Banks M, et al. The evolving role of endoscopy in the diagnosis of premalignant gastric lesions. F1000Res 2018;7.

27. Malfertheiner P, Fry LC, Monkemuller K. Can gastric cancer be prevented by Helicobacter pylori eradication? Best Pract Res Clin Gastroenterol 2006;20:709-19.

28. Chen HN, Wang Z, Li X, et al. Helicobacter pylori eradication cannot reduce the risk of gastric cancer in patients with intestinal metaplasia and dysplasia: evidence from a meta-analysis. Gastric Cancer 2016;19:166-75.

29. Rokkas T, Rokka A, Portincasa P. A systematic review and meta-analysis of the role of Helicobacter pylori eradication in preventing gastric cancer. Ann Gastroenterol 2017;30:414-23.

30. Choi IJ, Kook MC, Kim YI, et al. Helicobacter pylori
Therapy for the Prevention of Metachronous Gastric Cancer. N Engl J Med 2018;378:1085-95.

31. Shichijo S, Hirata Y, Niikura R, et al. Histologic intestinal metaplasia and endoscopic atrophy are predictors of gastric cancer development after Helicobacter pylori eradication. Gastrointest Endosc 2016;84:618-24.

32. Rugge M, Correa P, Dixon MF, et al. Gastric mucosal atrophy: interobserver consistency using new criteria for classification and grading. Aliment Pharmacol Ther 2002;16:1249-59.

33. Banks M, Graham D, Jansen M, et al. British Society of Gastroenterology guidelines on the diagnosis and management of patients at risk of gastric adenocarcinoma. Gut 2019;68:1545-75.

34. Leja M, Funka K, Janciauskas D, et al. Interobserver variation in assessment of gastric premalignant lesions: higher agreement for intestinal metaplasia than for atrophy. Eur J Gastroenterol Hepatol 2013;25:694-9.

35. Offerhaus GJ, Price AB, Haot J, et al. Observer agreement on the grading of gastric atrophy. Histopathology 1999;34:320-5.

36. Yue H, Shan L, Bin L. The significance of OLGA and OLGIM staging systems in the risk assessment of gastric cancer: a systematic review and meta-analysis. Gastric Cancer 2018;21:579-87.

37. Song H, Held M, Sandin S, et al. Increase in the Prevalence of Atrophic Gastritis Among Adults Age 35 to 44 Years Old in Northern Sweden Between 1990 and 2009. Clin Gastroenterol Hepatol 2015;13:1592-600.e1.

38. Choi CE, Sonnenberg A, Turner K, et al. High Prevalence of Gastric Preneoplastic Lesions in East Asians and Hispanics in the USA. Dig Dis Sci 2015;60:2070-6.

39. Asaka M, Sugiyama T, Nobuta A, et al. Atrophic gastritis and intestinal metaplasia in Japan: results of a large multicenter study. Helicobacter 2001;6:294-9.

40. O'Connor A, McNamara D, O'Morain CA. Surveillance of gastric intestinal metaplasia for the prevention of gastric cancer. Cochrane Database Syst Rev 2013;9:CD009322.

41. Spence AD, Cardwell CR, McMenamin UC, et al. Adenocarcinoma risk in gastric atrophy and intestinal metaplasia: a systematic review. BMC Gastroenterol 2017;17:157.

42. Zullo A, Hassan C, Romiti A, et al. Follow-up of intestinal metaplasia in the stomach: When, how and why. World J Gastrointest Oncol 2012;4:30-6.

43. Eriksson NK, Karkkainen PA, Farkkila MA, et al. Prevalence and distribution of gastric intestinal metaplasia and its subtypes. Dig Liver Dis 2008;40:355-60. 
44. Olmez S, Aslan M, Erten R, et al. The Prevalence of Gastric Intestinal Metaplasia and Distribution of Helicobacter pylori Infection, Atrophy, Dysplasia, and Cancer in Its Subtypes. Gastroenterol Res Pract 2015;2015:434039.

45. Yaghoobi M, Bijarchi R, Narod SA. Family history and the risk of gastric cancer. Br J Cancer 2010;102:237-42.

46. de Vries AC, van Grieken NC, Looman CW, et al. Gastric cancer risk in patients with premalignant gastric lesions: a nationwide cohort study in the Netherlands. Gastroenterology 2008;134:945-52.

47. Park YH, Kim N. Review of atrophic gastritis and intestinal metaplasia as a premalignant lesion of gastric cancer. J Cancer Prev 2015;20:25-40.

48. Cassaro M, Rugge M, Gutierrez O, et al. Topographic patterns of intestinal metaplasia and gastric cancer. Am J Gastroenterol 2000;95:1431-8.

49. Song H, Ekheden IG, Zheng Z, et al. Incidence of gastric cancer among patients with gastric precancerous lesions: observational cohort study in a low risk Western population. BMJ 2015;351:h3867.

50. Sung JK. Diagnosis and management of gastric dysplasia. Korean J Intern Med 2016;31:201-9.

51. Correa P. Clinical implications of recent developments in gastric cancer pathology and epidemiology. Semin Oncol 1985;12:2-10.

52. Lauwers GY, Srivastava A. Gastric preneoplastic lesions and epithelial dysplasia. Gastroenterol Clin North Am 2007;36:813-29, vi.

53. Baek DH, Kim GH, Park DY, et al. Gastric epithelial dysplasia: characteristics and long-term follow-up results after endoscopic resection according to morphological categorization. BMC Gastroenterol 2015;15:17.

54. Yoshihara M, Sumii K, Haruma K, et al. Correlation of ratio of serum pepsinogen I and II with prevalence of gastric cancer and adenoma in Japanese subjects. Am J Gastroenterol 1998;93:1090-6.

55. Goddard AF, Badreldin R, Pritchard DM, et al. The management of gastric polyps. Gut 2010;59:1270-6.

56. Ahn JY, Son DH, Choi KD, et al. Neoplasms arising in large gastric hyperplastic polyps: endoscopic and pathologic features. Gastrointest Endosc 2014;80:1005-13.e2.

57. Laine L, Cohen H, Sloane R, et al. Interobserver agreement and predictive value of endoscopic findings for H. pylori and gastritis in normal volunteers. Gastrointest Endosc 1995;42:420-3.

58. Yagi K, Nakamura A, Sekine A. Comparison between magnifying endoscopy and histological, culture and urease test findings from the gastric mucosa of the corpus. Endoscopy 2002;34:376-81.

59. Anagnostopoulos GK, Yao K, Kaye P, et al. Highresolution magnification endoscopy can reliably identify normal gastric mucosa, Helicobacter pylori-associated gastritis, and gastric atrophy. Endoscopy 2007;39:202-7.

60. Pimentel-Nunes P, Dinis-Ribeiro M, Soares JB, et al. A multicenter validation of an endoscopic classification with narrow band imaging for gastric precancerous and cancerous lesions. Endoscopy 2012;44:236-46.

61. Pimentel-Nunes P, Libanio D, Lage J, et al. A multicenter prospective study of the real-time use of narrow-band imaging in the diagnosis of premalignant gastric conditions and lesions. Endoscopy 2016;48:723-30.

62. Kanzaki H, Uedo N, Ishihara R, et al. Comprehensive investigation of areae gastricae pattern in gastric corpus using magnifying narrow band imaging endoscopy in patients with chronic atrophic fundic gastritis. Helicobacter 2012;17:224-31.

63. Uedo N, Yao K. Endoluminal Diagnosis of Early Gastric Cancer and Its Precursors: Bridging the Gap Between Endoscopy and Pathology. Adv Exp Med Biol 2016;908:293-316.

64. Yao K, Iwashita A, Tanabe H, et al. White opaque substance within superficial elevated gastric neoplasia as visualized by magnification endoscopy with narrowband imaging: a new optical sign for differentiating between adenoma and carcinoma. Gastrointest Endosc 2008;68:574-80.

65. Nakayama Y, Horiuchi A, Kumagai T, et al. Discrimination of normal gastric mucosa from Helicobacter pylori gastritis using standard endoscopes and a single observation site: studies in children and young adults. Helicobacter 2004;9:95-9.

66. Redeen S, Petersson F, Jonsson KA, et al. Relationship of gastroscopic features to histological findings in gastritis and Helicobacter pylori infection in a general population sample. Endoscopy 2003;35:946-50.

67. Nomura S, Ida K, Terao S, et al. Endoscopic diagnosis of gastric mucosal atrophy: multicenter prospective study. Dig Endosc 2014;26:709-19.

68. White JR, Sami SS, Reddiar D, et al. Narrow band imaging and serology in the assessment of premalignant gastric pathology. Scand J Gastroenterol 2018;53:1611-8.

69. Kitahara F, Kobayashi K, Sato T, et al. Accuracy of screening for gastric cancer using serum pepsinogen concentrations. Gut 1999;44:693-7.

70. Huang YK, Yu JC, Kang WM, et al. Significance of 
Serum Pepsinogens as a Biomarker for Gastric Cancer and Atrophic Gastritis Screening: A Systematic Review and Meta-Analysis. PLoS One 2015;10:e0142080.

71. Kono S, Gotoda T, Yoshida S, et al. Can endoscopic atrophy predict histological atrophy? Historical study in United Kingdom and Japan. World J Gastroenterol 2015;21:13113-23.

72. Kimura KT, Takemoto T. An Endoscopic Recognition of the Atrophic Border and its Significance in Chronic Gastritis. Endoscopy 1969;1:87-97.

73. Yao K, Oishi T, Matsui T, et al. Novel magnified endoscopic findings of microvascular architecture in intramucosal gastric cancer. Gastrointest Endosc 2002;56:279-84.

74. Dai YC, Tang ZP, Zhang YL. How to assess the severity of atrophic gastritis. World J Gastroenterol 2011;17:1690-3.

75. Areia M, Amaro P, Dinis-Ribeiro M, et al. External validation of a classification for methylene blue magnification chromoendoscopy in premalignant gastric lesions. Gastrointest Endosc 2008;67:1011-8.

76. Kono Y, Takenaka R, Kawahara Y, et al. Chromoendoscopy of gastric adenoma using an acetic acid indigocarmine mixture. World J Gastroenterol 2014;20:5092-7.

77. Inoue $\mathrm{T}$, Uedo N, Ishihara R, et al. Autofluorescence imaging videoendoscopy in the diagnosis of chronic atrophic fundal gastritis. J Gastroenterol 2010;45:45-51.

78. Gono K, Obi T, Yamaguchi M, et al. Appearance of enhanced tissue features in narrow-band endoscopic imaging. J Biomed Opt 2004;9:568-77.

79. So J, Rajnakova A, Chan YH, et al. Endoscopic tri-modal imaging improves detection of gastric intestinal metaplasia among a high-risk patient population in Singapore. Dig Dis Sci 2013;58:3566-75.

80. Shi J, Jin N, Li Y, et al. Clinical study of autofluorescence imaging combined with narrow band imaging in diagnosing early gastric cancer and precancerous lesions. J BUON 2015;20:1215-22.

81. Eshmuratov A, Nah JC, Kim N, et al. The correlation of endoscopic and histological diagnosis of gastric atrophy. Dig Dis Sci 2010;55:1364-75.

82. Nagata N, Shimbo T, Akiyama J, et al. Predictability of Gastric Intestinal Metaplasia by Mottled Patchy Erythema Seen on Endoscopy. Gastroenterology Res 2011;4:203-9.

83. Yao K, Iwashita A, Nambu M, et al. Nature of white opaque substance in gastric epithelial neoplasia as visualized by magnifying endoscopy with narrow-band imaging. Dig Endosc 2012;24:419-25.

84. Uedo N, Ishihara R, Iishi H, et al. A new method of diagnosing gastric intestinal metaplasia: narrowband imaging with magnifying endoscopy. Endoscopy 2006;38:819-24.

85. Kanemitsu T, Yao K, Nagahama T, et al. Extending magnifying NBI diagnosis of intestinal metaplasia in the stomach: the white opaque substance marker. Endoscopy 2017;49:529-35.

86. Song J, Zhang J, Wang J, et al. Meta-analysis: narrow band imaging for diagnosis of gastric intestinal metaplasia. PLoS One 2014;9:e94869.

87. Ang TL, Pittayanon R, Lau JY, et al. A multicenter randomized comparison between high-definition white light endoscopy and narrow band imaging for detection of gastric lesions. Eur J Gastroenterol Hepatol 2015;27:1473-8.

88. Axon A. Symptoms and diagnosis of gastric cancer at early curable stage. Best Pract Res Clin Gastroenterol 2006;20:697-708.

89. Kaise M, Kato M, Urashima M, et al. Magnifying endoscopy combined with narrow-band imaging for differential diagnosis of superficial depressed gastric lesions. Endoscopy 2009;41:310-5.

90. Capelle LG, Haringsma J, de Vries AC, et al. Narrow band imaging for the detection of gastric intestinal metaplasia and dysplasia during surveillance endoscopy. Dig Dis Sci 2010;5 5:3442-8.

91. Ribeiro H, Libanio D, Castro R, et al. Reliability of Paris Classification for superficial neoplastic gastric lesions improves with training and narrow band imaging. Endosc Int Open 2019; 7:E633-E40.

92. Zhao Z, Yin Z, Wang S, et al. Meta-analysis: The diagnostic efficacy of chromoendoscopy for early gastric cancer and premalignant gastric lesions. J Gastroenterol Hepatol 2016;31:1539-45.

93. Dinis-Ribeiro M, Areia M, de Vries AC, et al. Management of precancerous conditions and lesions in the stomach (MAPS): guideline from the European Society of Gastrointestinal Endoscopy (ESGE), European Helicobacter Study Group (EHSG), European Society of Pathology (ESP), and the Sociedade Portuguesa de Endoscopia Digestiva (SPED). Endoscopy 2012;44:74-94.

94. Iguchi M, Kato J, Yoshida T, et al. Serum pepsinogen levels can quantify the risk of development of metachronous gastric cancer after endoscopic resection. Int J Cancer 2016;139:1150-6.

95. Teh JL, Tan JR, Lau LJ, et al. Longer examination time improves detection of gastric cancer during diagnostic upper gastrointestinal endoscopy. Clin Gastroenterol 
Hepatol 2015;13:480-7.e2.

96. Dixon MF, Genta RM, Yardley JH, et al. Classification and grading of gastritis. The updated Sydney System. International Workshop on the Histopathology of Gastritis, Houston 1994. Am J Surg Pathol 1996;20:1161-81.

97. El-Zimaity HM, Graham DY. Evaluation of gastric mucosal biopsy site and number for identification of Helicobacter pylori or intestinal metaplasia: role of the Sydney System. Hum Pathol 1999;30:72-7.

98. Buxbaum JL, Hormozdi D, Dinis-Ribeiro M, et al. Narrow-band imaging versus white light versus mapping biopsy for gastric intestinal metaplasia: a prospective blinded trial. Gastrointest Endosc 2017;86:857-65.

99. Xirouchakis E, Laoudi F, Tsartsali L, et al. Screening for gastric premalignant lesions with narrow band imaging, white light and updated Sydney protocol or both? Dig Dis Sci 2013;58:1084-90.

100. Vannella L, Lahner E, Osborn J, et al. Systematic review: gastric cancer incidence in pernicious anaemia. Aliment Pharmacol Ther 2013;37:375-82.

101.Hershko C, Ronson A, Souroujon M, et al. Variable

doi: $10.21037 / \operatorname{tgh} .2020 .03 .03$

Cite this article as: White JR, Banks M. Identifying the pre-malignant stomach: from guidelines to practice. Transl Gastroenterol Hepatol 2022;7:8. hematologic presentation of autoimmune gastritis: agerelated progression from iron deficiency to cobalamin depletion. Blood 2006;107:1673-9.

102.Lee JY, Kim N, Lee HS, et al. Correlations among endoscopic, histologic and serologic diagnoses for the assessment of atrophic gastritis. J Cancer Prev 2014;19:47-55.

103. Areia M, Dinis-Ribeiro M, Rocha Goncalves F. Cost-utility analysis of endoscopic surveillance of patients with gastric premalignant conditions. Helicobacter 2014;19:425-36.

104. Gomez JM, Wang AY. Gastric intestinal metaplasia and early gastric cancer in the west: a changing paradigm. Gastroenterol Hepatol (N Y) 2014;10:369-78.

105. Areia M, Carvalho R, Cadime AT, et al. Screening for gastric cancer and surveillance of premalignant lesions: a systematic review of cost-effectiveness studies. Helicobacter 2013;18:325-37.

106. Yeh JM, Hur C, Ward Z, et al. Gastric adenocarcinoma screening and prevention in the era of new biomarker and endoscopic technologies: a cost-effectiveness analysis. Gut 2016;65:563-74. 